\title{
AVALIAÇÃO DAS TELE-AULAS EM TEMPO DE COVID-19 PELOS ENCARREGADOS DE EDUCAÇÃO DE LUANDA
}

\author{
Chocolate Brás ${ }^{1}$ \\ https://orcid.org/0000-0003-3229-8369
}

Recebido: 10.01 .2021
Aceito: 04.06.2021
Publicado: 15.07 .2021

\section{RESUMO}

Este artigo estuda a implementação das tele-aulas em Angola, como uma das principais acções e medidas de política adoptadas pelo sector da educação em resposta à suspensão das actividades lectivas presenciais no país. O estudo tem como objectivo reflectir sobre os resultados da avaliação das tele-aulas feita pelos encarregados de educação da província de Luanda durante o período de Estado de Emergência. Trata-se de um estudo exploratório, cuja sustentação teórica é feita com suporte aos estudos de Souza \& Aguiar (2020) e Bahia (2020), articulados com a análise de relatórios do Ministério da Educação (2019; 2020), do Instituto Nacional de Estatística (2016; 2017), de alguns referentes bibliográficos internacionais, com particular realce para as recomendações da UNESCO (2020), OCDE (2020), Organização Mundial da Saúde (2020), estudos da EdTechHub \& Elearning Africa (2020) e da Save the Children International (2020). Para compreender a avaliação das tele-aulas realizou-se um inquérito por questionário online aplicado a cento e dezassete (117) encarregados de educação durante o mês de Abril do ano 2020 . O estudo concluiu que a produção das tele-aulas foi uma boa alternativa à suspensão das aulas presenciais, apesar de 23,1\% das crianças não as terem acompanhado por desatenção e falta de acompanhamento dos encarregados de educação, constantes de cortes de energia eléctrica e da sua falta em algumas zonas, associado à falta de sinal de televisão, bem como a não posse de aparelho de televisão da parte de alguns agregados familiares pela débil situação socioeconómica que os caracterizam.

Palavras-chave: Avaliação das tele-aulas; Cortes de energia eléctrica; Encarregados de Educação; Suspensão das aulas presenciais; Ministério da Educação.

\section{Evaluación de las tele-clases en tiempo de covid-19 por los encargados de educación de Luanda.}

\section{RESUMEN}

Este artículo estudia la implementación de las tele-clases en Angola, como una de las principales acciones y medidas de política adoptadas por el sector de la educación en respuesta a la suspensión de las actividades lectivas presenciales en el país. El estudio tiene como objetivo reflexionar sobre los resultados de la evaluación de las teleclases realizados por los encargados de educación de la provincia de Luanda durante el período de Estado de Emergencia. Se trata de un estudio exploratorio, cuya sustentación teórica es hecha con soporte a los estudios de Souza \& Aguiar (2020) y Bahia (2020), articulados con el análisis de informes del Ministerio de la Educación (2019; 2020), y del Instituto Nacional de Estadística (2016; 2017) de Angola, de algunos referentes bibliográficos internacionales, con particular realce en las recomendaciones de la UNESCO (2020), OCDE (2020), OMS (2020), estudios de la EdTechHub \& Elearning Africa (2020) y de Save the Children International (2020). Para comprender la evaluación de las teleclases se realizó una encuesta online aplicada a ciento y diecisiete (117) encargados de educación durante el mes de Abril del año 2020. El estudio concluyó que la producción de las teleclases fue una buena alternativa a la suspensión de las clases presenciales, a pesar del 23,1\% de los niños no las poder acompañar por desatención y falta de acompañamiento de los encargados de educación, constantes de cortes de energía eléctrica y su falta en algunas zonas, asociada a la falta de señal de televisión así como a la falta de posesión de un televisor por parte de algunos tutores por la débil situación socioeconómica que los caracteriza.

Palabras-clave: Evaluación de las teleclases; Cortes de energía eléctrica; Encargados de Educación; Suspensión de las clases presenciales; Ministerio de la Educación.

${ }^{1}$ Docente no curso de graduação em Pedagogia do Instituto Superior Politécnico Metropolitano de Angola - IMETRO (desde 2017). Doutorando em Educação no Programa de Pós-Graduação em Educação. Mestre em Administração Educacional; Possui Graduação em Ensino de Psicologia. Atualmente é Investigador Associado ao Centro de Estudos e Investigação Científica do IMETRO (CEICin) atuando na linha de pesquisa Educação: políticas públicas, formação de professores, prática docente e sociedade do trabalho. Email: chocolatebras@gmail.com; http://lattes.cnpq.br/6247510092938842 


\section{Evaluation of Educational TV in time of covid-19 by the head of education in Luanda.}

\section{ABSTRACT}

This article studies the implementation of educational TV in Angola, as one of the main actions and policy measures adopted by the education sector in response to the suspension of classroom teaching activities in the country. The study aims to reflect on the results of the evaluation of the educational TV done by the parents of education in the province of Luanda during the period of State of Emergency. This is an exploratory study, whose theoretical support is made with support to the studies of Souza \& Aguiar (2020) and Bahia (2020), articulated with the analysis of reports from the Ministry of Education (2019; 2020), the National Institute of Statistics $(2016 ; 2017)$, of some international bibliographic references, with particular emphasis for UNESCO (2020a; 2020b), OECD (2020), WHO (2020a; 2020b), studies by EdTechHub \& Elearning Africa (2020) and Save the Children International (2020). To understand the evaluation of the educational TV, an online questionnaire survey was applied to one hundred and seventeen (117) in charge of education during the month of April of the year 2020. The study concluded that the production of the educational TV was a good alternative of the suspension of face-to-face classes, although $23.1 \%$ of the children did not accompany them due to inattention and lack of follow-up by guardians, because of power cuts and their lack in some areas, associated with the lack of a television signal, as well as the lack of television equipment on the part of some households due to the weak socioeconomic situation that characterizes them.

Keywords: Evaluation of educational TV; Electricity cuts; Education chief, Education class suspension; Ministry of Education.

\section{Introdução}

A pandemia da COVID-19 afectou significativamente o sistema educativo mundial, condicionando as actividades lectivas presenciais e a gestão do processo de ensino-aprendizagem, motivando o encerramento generalizado de escolas em todos os países do mundo, tendo a quarentena institucional e domiciliar sido a medida imediata tomada pela maioria dos governos a nível global no sentido de estancar a sua propagação, além de outras medidas que garantissem o isolamento físico entre as pessoas, entendida pelas autoridades de saúde internacionais e nacionais como fundamentais para este efeito.

Dados da Organização das Nações Unidas para a Educação, a Ciência e a Cultura, de 18 de Março, apontavam que pelo menos cento e dois (102) países fecharam totalmente suas escolas e universidades, enquanto outros onze (11) decretaram fechamento parcial. Deste modo, esta organização multilateral considerou que metade dos estudantes do mundo, ou seja, mais de oitocentos e cinquenta milhões (850.000.000) de crianças, adolescentes e jovens estavam sem aulas devido à pandemia da COVID-19 (UNESCO, 2020a). Mais adiante, isto é, entre os meses de Abril e Maio, a UNESCO estimava que mais de 1,7 bilhões de crianças e jovens ficaram sem aulas presenciais, devido à suspensão de aulas na maioria dos países do mundo.

Angola não foi excepção, tendo suspendido as aulas em todos os subsistemas de ensino a partir de 24 de Março, um dia antes da declaração do Estado de Emergência no país, que passou a ter efeitos a partir do dia 27 do referido mês, implicando a suspensão de liberdades, direitos e garantias fundamentais dos cidadãos. Com a suspensão das actividades lectivas presenciais por meio do Decreto Executivo n. ${ }^{\circ}$ 01/20, de 19 de Março, do Ministério da Educação (Ministério da Educação, 2020a), perto de onze milhões (11.000.000) de alunos das instituições de ensino geral públicas, público-privadas e privadas ficaram sem aulas. De igual modo, ficaram sem poder ministrar aulas perto de duzentos mil (200.000) professores das diferentes classes do subsistema de ensino geral público e público-privado (Ministério da Educação, 2020d).

A crise pandémica levou a que as autoridades dos sectores da educação adoptassem um conjunto de medidas para aliviar o impacto da pandemia na educação. A nível do subsistema de ensino geral, foi adoptada o ensino à distância por meio das tele-aulas e rádio-aulas, desde 2 de Abril de 2020, transmitidas na Televisão Pública de Angola (TPA) e na Rádio Nacional de Angola (RNA) com o propósito de garantir a continuidade do processo de ensino e aprendizagem dos alunos, beneficiando perto de oito milhões (8.000.000), correspondentes aos alunos da Educação PréEscolar, Ensino Primário e I Ciclo do Ensino Secundário (Ministério da Educação, 2020d).

A implementação do projecto tele-aulas e rádio-aulas é uma resposta do sector da educação à suspensão das aulas presenciais motivada pela pandemia da COVID-19. Uma pandemia baseada 
no vírus SARS-CoV-2, que inicialmente foi caracterizada pela Organização Mundial da Saúde (OMS) como uma pneumonia de causa desconhecida, detectada em Wuhan, República Popular da China, tendo sido relatada pela primeira vez ao seu escritório no dia 31 de Dezembro de 2019. Depois de terem sido notificados os primeiros casos de infecção por este vírus na cidade de Wuham, a mesma espalhou-se por todos os continentes de forma vertiginosa tendo uma alta taxa de morbidade e mortalidade (Organização Mundial da Saúde, 2020a).

Até ao dia 30 de Janeiro de 2020, tinham sido registados a nível global um total de seis mil e sessenta e cinco (6.065) casos confirmados, com duzentos e treze (213) óbitos. Destes, oitenta e dois (82) casos foram diagnosticados em dezoito (18) países fora da China e não tinham sido registadas mortes fora do país asiático (Organização Mundial da Saúde, 2020b). Nessa mesma data, a OMS declarou a COVID-19 como uma emergência sanitária internacional com base na rápida expansão da circulação vírus para outros países (Comissão Interministerial para ss Emergências, 2020).

Infelizmente, a COVID-19 continuava a propagar-se de forma vertiginosa pelo mundo e a provocar incontrolados casos positivos de contágio e mortes, o que viria a motivar a OMS a considerá-la como uma Pandemia no dia 11 de Março de 2020. Em Angola, o primeiro alerta registou-se na segunda quinzena de Janeiro de 2020 como aponta a Comissão Interministerial para as Emergências que refere que o caso suspeito chegou a 16 Janeiro à cidade de Luanda vindo da cidade de Li-Hua tendo sido notificado as autoridades sanitárias, que prontamente foi monitorado e avaliado, tendo testado negativo à COVID-19, mas positivo ao Influenza A que é uma gripe comum (Comissão Interministerial para as Emergências, 2020, p.2).

Não obstante às medidas tomadas pela Comissão Interministerial para o combate à COVID-19, criada pelo Presidente da República de Angola, coordenada pela Ministra da Saúde e pelo Ministro do Interior, a 21 de Março, foram anunciados os primeiros dois casos positivos em território angolano, o que viria a reforçar as motivações para o Presidente da República decretar o Estado de Emergência em todo território nacional, por um período de 15 dias, com efeitos a partir de 27 de Março de 2020.

Em resposta ao impacto da pandemia da COVID-19 na educação, o Ministério da Educação aprovou as recomendações para o funcionamento das escolas no período de suspensão das aulas por meio do Decreto Executivo no 02/20, de 20 de Março (Ministério da Educação, 2020b), e criou por despacho interno um Comitê de Emergência do Sector, integrado por diversas Direcções nacionais, Gabinetes provinciais e Parceiros sociais nacionais e internacionais. De forma sintética, as acções e medidas de políticas adoptadas pelo Ministério da Educação para responder a pandemia da COVID-19 estiveram assentes no seguinte:

1. Suspensão das aulas em todas as escolas do país;

2. Aprovação das recomendações de actividades para os professores, gestores escolares, alunos e encarregados de educação durante o período de suspensão das aulas presenciais;

3. Implementação de um programa de ensino a distância para as classes da Iniciação a $9^{a}$ Classe por meio da televisão e da rádio;

4. Aprovação e implementação de um Plano de Resposta do Sector da Educação para a COVID-19;

5. Preparação de condições técnicas, materiais e humanas para a retoma das aulas presenciais em todas as escolas do país.

Posto isso, é de aludir que este artigo tem o propósito reflectir sobre os resultados da avaliação das tele-aulas feita pelos encarregados de educação da província de Luanda durante o período de Estado de Emergência. Em termos de estrutura o estudo começa por fundamentar o contexto histórico-social das tele-aulas, descrever o processo de planificação e gestão das tele-aulas, apresentar e analisar os resultados da avaliação, a fim de chegar às considerações finais.

Pelo seu objectivo e características, o presente estudo enquadra-se no domínio das pesquisas exploratórias, que na óptica de Gil (1999) têm o propósito de aprimorar hipóteses, validar instrumentos e proporcionar familiaridade com o campo de estudo, constituindo uma das 
primeiras fases de um estudo mais amplo. No contexto em referência, o estudo que se apresenta é um recorte do relatório de investigação sobre a educação e ensino em Angola em tempo da COVID-19 que foi realizado entre os meses de Abril a Julho de 2020, considerando a necessidade de analisar as principais acções e medidas de políticas adoptadas pelos Ministérios da Educação e do Ensino Superior, Ciência, Tecnologia e Inovação em resposta à pandemia da COVID-19.

\section{Planificação e Gestão das tele-aulas}

A implementação do ensino a distância por meio da transmissão de tele-aulas pode ser considerada como a principal resposta do sector da educação à suspensão de aulas presenciais nas instituições de ensino do subsistema de ensino geral em Angola. A sua transmissão na Televisão Pública de Angola (TPA) resultou de um protocolo de cooperação celebrado entre o Ministério da Educação e Ministério da Comunicação Social, rubricado no dia 1 de Abril de 2020 (Televisão Pública de Angola, 2020).

A informação da assinatura do referido protocolo foi veiculada no Telejornal da TPA na noite do dia 1 de Abril. Para o êxito das tele-aulas, a Ministra da Educação recomendou a participação activa dos encarregados de educação, isto é, garantindo as condições fundamentais para que os filhos e/ou educandos pudessem as acompanhar (Televisão Pública de Angola, 2020)

Do apelo da Ministra da Educação, sobressaiu-se a necessidade dos encarregados de educação, que igualmente estavam a observar a quarentena domiciliar, no âmbito do confinamento social imposto pelo Estado de Emergência ${ }^{2}$, preparar e acompanhar os seus filhos durante as transmissões das aulas e motivá-los para a realização de tarefas orientadas pelos professores durante as tele-aulas, de modo não só a garantir que o seu educando aprenda, mas de motivá-lo neste processo de reforço das aprendizagens. Esse apelo é importante, pois, como aponta Brás (2018), a participação dos encarregados de educação na educação dos filhos, além de ser um elemento motivador, conduz à melhoria dos resultados das aprendizagens e leva a que os encarregados de educação tenham uma melhor representação social da escola, enquanto espaço formal de construção social do cidadão.

As tele-aulas, enquanto resposta das autoridades do sector da educação, surgem no seguimento das orientações internacionais sobre a escolha de melhores formas de responder à pandemia da COVID-19, tal como recomendaram a UNESCO e a OCDE ${ }^{3}$. A UNESCO, no dia 06 de Março, publicou dez (10) recomendações sobre o ensino a distância, de modo a fazer face à suspensão das aulas e ao fecho das instituições de ensino em todo mundo, que dias depois partilhou as respectivas estratégias e respostas com os Ministros da Educação dos vários países (UNESCO, 2020b). Das suas 10 recomendações, podem destacar-se as seguintes que estão directamente ligadas ao objecto deste estudo:

- Analisar a resposta e escolher as melhores ferramentas. Nesta recomendação, estabelecia-se a necessidade de escolher as tecnologias mais adequadas de acordo com os serviços de energia eléctrica e telecomunicações dos países, bem como as capacidades dos alunos e professores. Podendo incluir-se nesta necessidade a questão das plataformas na Internet, lições de vídeo e até transmissão por meio da televisão ou rádio.

A compreensão da resposta das autoridades da educação em Angola está ligada a esta recomendação, que, em verdade, constitui a primeira das 10 recomendações da UNESCO. Não obstante aos problemas de distribuição da energia eléctrica no país que em parte terá condicionado o impacto desta resposta à pandemia. Pois, os dados do Inquérito de Indicadores Múltiplos e de Saúde (IIMS) 2015-2016 publicados pelo Instituto Nacional de Estatística atestam que há uma assimetria no acesso à electricidade em Angola, em que 64\% dos agregados familiares na área

\footnotetext{
2 Trata-se de uma situação de excepção, susceptível de suspender ou limitar o exercício dos direitos, liberdades e garantias dos cidadãos. Em termos gerais, é um Estado de anormalidade inconstitucional resultante de uma situação que periga a paz social e o bem-estar dos cidadãos, tal como estabelece a Lei n. ${ }^{\circ} 17 / 91$, de 11 de Maio (Assembleia do Povo, 1991). Considerando a crise pandémica, ela foi declarada pela primeira vez em Angola por meio do Decreto Presidencial n. ${ }^{\circ}$ 81/20, de 25 de Março (Assembleia Nacional, 2020a).

${ }^{3}$ Organização para Cooperação e Desenvolvimento Económico.
} 
urbana possuem electricidade contra 7\% de agregados que a possuem na área rural (Instituto Nacional de Estatística, 2017).

- Assegurar-se de que os programas são inclusivos. Esta recomendação considerava que era fundamental que se implementassem medidas que garantissem o acesso de estudantes de baixa renda ou com deficiências, podendo para o efeito se ponderar a instalação de computadores dos laboratórios da escola na casa dos alunos e ajudar com a ligação à internet.

Partindo desta recomendação e considerando a metodologia adoptada pelas autoridades da educação em Angola (tele-aulas), associado ao ainda difícil acesso à electricidade está a questão das condições socioeconómicas das famílias, sobretudo na posse de bens essenciais, como é o caso de aparelhos electrónicos, tais como a televisão e rádio. Em Angola, a posse de rádio é de $63 \%$ nas áreas urbanas contra 32\% nas áreas rurais, enquanto a fruição de televisão é de $75 \%$ nas áreas urbanas contra 14\% nas áreas rurais (Instituto Nacional de Estatística, 2017). Portanto, pode-se daqui deduzir que as tele-aulas poderiam não ser tão inclusivos conforme se pretendia na resposta à pandemia da COVID-19.

- Criar regras e avaliar a aprendizagem dos alunos. Esta recomendação remete às autoridades da educação a definição de regras com encarregados de educação e alunos, bem como a criação de testes e exercícios para avaliar de perto a aprendizagem dos alunos e facilitar o envio da avaliação para os alunos, evitando sobrecarregar os encarregados de educação.

Sobre esta recomendação, é importante esclarecer que a filosofia das tele-aulas adoptada pelas autoridades da educação em Angola não tinha a componente avaliativa, apenas de reforço de aprendizagem e manutenção das rotinas das crianças e adolescentes. Tendo em conta o carácter atípico da medida para muitos alunos, encarregados de educação que experimentaram pela primeira vez poderá ter sido uma medida acertada em nosso entender.

Quanto às recomendações da OCDE, impõe-se referir que no dia 30 de Março de 2020, apresentou no seu relatório um roteiro para guiar a resposta educacional à pandemia, onde propunha que os líderes dos sistemas e organizações educacionais desenvolvessem planos para a continuidade da educação por meio de modalidades alternativas, durante o período de isolamento social necessário e igualmente oferecia um quadro de áreas a serem cobertas por tais planos. Recomendou que os líderes educacionais adoptassem uma abordagem proactiva para contribuir para a mitigação do impacto da pandemia COVID-19 e para prevenir a perda de aprendizagem durante o período de distanciamento social (OCDE, 2020).

Para todos os efeitos, a planificação e a gestão das tele-aulas foram asseguradas por uma comissão criada pela Ministra da Educação, supervisionada pelo Secretário de Estado para a Educação PréEscolar e pelo Secretário de Estado para o Ensino Secundário. A comissão tinha duas coordenações. A primeira coordenação era a responsável pela produção das aulas para a classe de iniciação (Educação Pré-Escolar) e todas do Ensino Primário (da $1^{\mathrm{a}}$ a $6^{\mathrm{a}}$ Classes) liderada pelo Instituto Nacional de Formação de Quadros da Educação (INFQE) e a segunda coordenação era a responsável pela produção das aulas das classes do I Ciclo do Ensino Secundário (da $7^{\mathrm{a}}$ a $9^{\mathrm{a}}$ Classes) liderada pelo Instituto Nacional de Investigação e Desenvolvimento da Educação (INIDE). Importa referir que ambas coordenações contavam com os préstimos dos técnicos do Instituto Nacional de Ensino Especial (INEE) e da Direcção Nacional do Ensino Geral (DNEG) todos afectos ao Ministério da Educação (Instituto Nacional de Formação de Quadros da Educação, 2020).

A equipa técnica da comissão era constituída por cem (100) pessoas, entre professores, supervisores, metodólogos, gestores escolares, responsáveis do Gabinete Provincial da Educação de Luanda, técnicos da Televisão Pública de Angola e da Rádio Nacional de Angola, bem como de outros serviços de apoio logístico (Instituto Nacional de Formação de Quadros da Educação, 2020). Dos membros da equipa técnica destaca-se a equipa de produção das aulas constituída por 75 membros, dos quais 35 professores da Classe de Iniciação e do Ensino Primário, 22 professores do I Ciclo do Ensino Secundário, 12 Metodólogos e 6 supervisores pedagógicos. 
Quadro 1 - Equipa de Produção das tele-aulas

\begin{tabular}{ccc}
\hline Categoria & Fr. & Percentagem (\%) \\
\hline Supervisores & 6 & 8 \\
\hline Metodólogos & 12 & 16 \\
\hline $\begin{array}{c}\text { Professores da Classe de Iniciação e do Ensino } \\
\text { Primário }\end{array}$ & 35 & 46,6 \\
\hline Professores do I Ciclo do Ensino Secundário & 22 & 29,3 \\
\hline Total & $\mathbf{7 5}$ & $\mathbf{1 0 0}$ \\
\hline
\end{tabular}

Fonte: Instituto Nacional de Formação de Quadros da Educação (2020).

Em termos de planificação, as tele-aulas obedeciam a seguinte organização (sistematização): (i) elaboração do plano ou guião da aula; (ii) preparação dos meios de ensino; (iii) apoio tutorial (simulação da aula); (iv) gravação da aula; (v) edição da aula; e (vi) transmissão da aula. O processo de gravação e de edição foram caracterizados pela equipa técnica como o mais complexo. Nas gravações, sobressaíram dificuldades de domínio da Língua Portuguesa e de adopção de metodologias mais actuais e eficazes de ministração das aulas por parte de alguns professores seleccionados/recrutados para as tele-aulas na primeira fase, sobretudo com os professores do Ensino Primário, o que levava a que uma aula com a duração de vinte (20) minutos fosse gravada em pelo menos uma (1) hora por sucessivos cortes motivado pelos erros cometidos no momento da gravação (Instituto Nacional de Formação de Quadros da Educação, 2020).

Em relação à edição das aulas, um dos grandes handicaps segundo a equipa técnica foi a qualidade dos materiais de filmagem da TPA, que nem sempre gravavam com a qualidade pretendida, além do facto de, às vezes, a gravação ser perdida e obrigar a regravação. Mas, a principal dificuldade inicialmente foi a inserção da tradução da aula em Língua Gestual Angolana (LGA), que era fundamental para a garantia da inclusão dos alunos com necessidades educativas especiais (dificuldades auditivas). Por exemplo, em termos procedimentais, no processo de gravação não se podia integrar o especialista de LGA, pois na fase de edição em que são por norma feitos cortes e alinhamento de partes, a referida tradução poderia ficar "amputada", situação que se verificou durante o primeiro mês de emissão das tele-aulas. A partir do mês de Maio de 2020 já foi possível integrar a LGA nas tele-aulas, aumentando a sua eficiência e eficácia.

\section{Transmissão das tele-aulas}

As tele-aulas eram transmitidas no horário das 11:30 às 13:30 na TPA, cada aula tinha a duração de vinte (20) minutos, tempo que obedecia às recomendações da UNESCO. Na Educação PréEscolar, isto é, classe de iniciação, foram ministradas aulas de três (3) disciplinas, nomeadamente, (i) Comunicação Linguística, (ii) Representação Matemática, e (iii) Meio Físico e Social. Da $1^{\text {a }}$ a $6^{\mathrm{a}}$ Classe era ministradas aulas de 4 (quatro) disciplinas: (i) Língua Portuguesa, (ii) Matemática, (iii) Estudo do Meio, e (iv) Ciências da Natureza.

A fixação do horário de duração das tele-aulas obedeceu aos preceitos estabelecidos pela UNESCO enquadradas na recomendação $n .{ }^{\circ} 9$ das suas dez (10) recomendações para o ensino a distância em resposta à pandemia da COVID-19, que consiste em definir a duração das unidades com base na capacidade dos alunos, em que se recomendava a manutenção de um calendário de acordo com a capacidade dos alunos se concentrarem sozinhos, sobretudo para aulas por videoconferência. Sendo preferível que cada unidade não excedesse os vinte (20) minutos para o ensino primário e quarenta (40) minutos para o ensino secundário (UNESCO, 2020b).

Para uma melhor compreensão da planificação das tele-aulas para a Educação Pré-Escolar e Ensino Primário, apresenta-se na ilustração a seguir a distribuição de disciplinas por classe e horários. 
Figura 1 - Horário de transmissão das tele-aulas na TPA

\section{ANGÓLA ESCOLINHA EM CASA tpa 2}

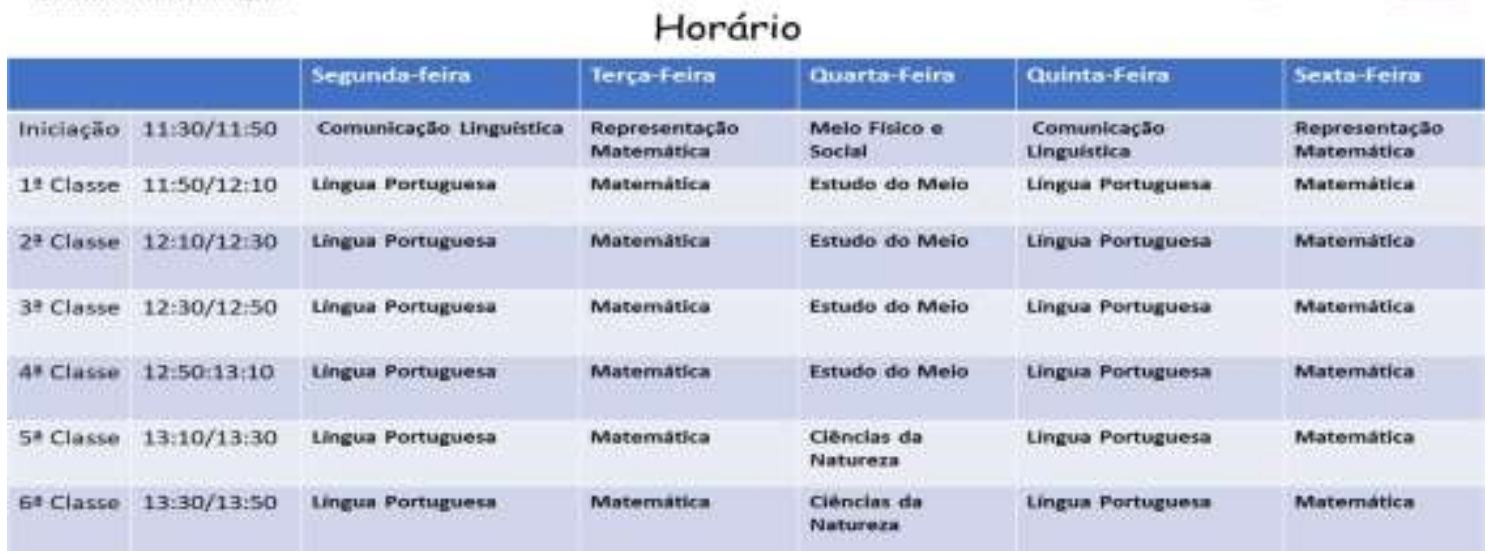

Fonte: Instituto Nacional de Formação de Quadros da Educação (2020).

Durante o mês de Abril eram produzidas apenas as tele-aulas da Classe de iniciação e as classes do Ensino Primário, isto é, da $1^{\mathrm{a}}$ a $6^{\mathrm{a}}$ classe, por razões técnicas e operacionais, considerando a emergência em que o projecto foi implementado. A situação veio ser alterada a 4 de Maio de 2020 quando elas começaram a ser transmitidas para os alunos do I Ciclo do Ensino Secundário, processo sob gestão processual do INIDE, com a colaboração de escolas públicas e privadas de Luanda. As aulas para este ciclo do Ensino Secundário ( $7^{\mathrm{a}}$ a $9^{\mathrm{a}}$ Classe) eram de Língua Portuguesa, Matemática, Física, Química e Biologia, que ocorriam de segunda a sexta-feira.

A implementação do ensino a distância, por meio de tele-aulas, que ocorreu em Angola, por força da pandemia COVID-19, peca por tardia, porquanto a sua implantação já estava estabelecida quer na Lei de Bases do Sistema Educativo que vigorou do ano de 2001 a 2016, decorrente da Lei 13/01, de 31 de Dezembro (ANGOLA, 2001), e na Lei de Bases do Sistema de Educação e Ensino em vigor, isto é, Lei n. ${ }^{\circ}$ 32/20, de 12 de Agosto - Lei que altera a lei n. ${ }^{\circ}$ 17/16, de 7 de Outubro Lei de Bases do Sistema de Educação e Ensino (Assembleia Nacional, 2020b), desde 2016 por meio da Lei n. ${ }^{\circ} 17 / 16$, de 7 de Outubro (Assembleia Nacional, 2016).

Essas leis de bases consagram o ensino a distância como uma das modalidades da educação em Angola, sendo transversal a todos os subsistemas de ensino. Mas, a sua efectivação esteve condicionada a falta de regulamentação própria conforme estabeleciam as referidas leis, bem como de uma eventual dificuldade em planificar e criar condições técnicas, tecnológicas, materiais e humanas para essa modalidade de ensino no país.

Neste sentido, deve-se assinalar a realização do I Seminário Internacional sobre a Educação a Distância e Itinerante pelo Ministério da Educação, no mês de Novembro de 2019, como um marco para a inversão da situação e conducente à adopção de medidas de política que viabilizassem as condições fundamentais para a implementação efectiva do ensino a distância em Angola.

Segundo o Ministério da Educação, o seminário cumpriu a primeira etapa de um projecto que compreende três etapas que visam revitalizar a ensino a distância em Angola. A segunda etapa, por meio de esforços concertados entre as estruturas centrais e entidades locais, incidiria sobre a realização de acções de formação presencial e a distância sobre a educação a distância e educação itinerante, sobre as estratégias de recuperação escolar de alunos fora do sistema de ensino, 
preferencialmente da Classe de Iniciação e das $1^{\mathrm{a}}$ e $2^{\mathrm{a}}$ Classes do ensino primário (Ministério da Educação, 2019).

A terceira fase decorreria, em termos experimentais, em duas escolas daquelas províncias que apresentarem mais elevado défice de acesso escolar, designadamente na classe de iniciação e nas $1^{\mathrm{a}}$ e $2^{\mathrm{a}}$ Classes do ensino primário, todas de frequência obrigatória de acordo com a Lei de Bases do Sistema de Educação e Ensino (Ministério da Educação, 2019).

Portanto, a COVID-19, neste sentido, veio confirmar que se precisava apostar seriamente na criação de condições para a implementação do ensino a distância, nomeadamente ambientes virtuais de aprendizagem, formação de professores e agentes administrativos, sem descorar da melhoria do fornecimento da energia eléctrica e das telecomunicações e tecnologias de informação no país. Importa com isso realçar com clareza a importância da revolução digital e do ensino a distância, sabendo que já não é possível conceber um Plano de Desenvolvimento Institucional descartando as TIC's num sector como da educação e ensino sendo um sector decisivo e estratégico para o desenvolvimento do país no presente e no futuro.

\section{Método}

Com recurso ao questionário, buscou-se responder à pergunta de partida: "que avaliação os encarregados de educação fazem das tele-aulas transmitidas no período de Estado de Emergência em Angola?". Para o efeito, organizou-se o questionário em torno de nove (9) perguntas cujas respostas são apresentadas e analisados no ponto 4. O questionário foi distribuído aos encarregados de educação por via das plataformas digitais Facebook e WhatsApp, no dia 27 de Abril de 2020.

Trata-se de questionário online com recurso à ferramenta Google Forms, que é um formulário Google que permite ao usuário recolher e organizar gratuitamente informações maiores e menores (Google, 2017), cujas respostas são armazenadas em planilhas (Google Sheets) e podem ser visualizadas em gráficos ou mesmo de forma bruta na planilha.

Sobre a utilização deste instrumento, Mathias \& Sakai (2013) referem que o levantamento de dados e opiniões podem ser facilmente realizados no referido programa e que todos os tipos de questões, havendo a possibilidade de tornar a(s) pergunta(s) obrigatória(s), de modo que o questionário só é enviado se todas as questões obrigatórias estiverem respondidas. O formulário construído pode ser disponibilizado por meio de um endereço electrónico e, em quando preenchido pelos respondentes, as respostas aparecem imediatamente na página do usuário que o criou.

Importa destacar que se divulgou ao máximo a distribuição do questionário por meio de partilhas nas redes sociais e fizeram-se postagens como lembretes entre os dias 28 e 30 de Abril, dia antes do fim da colecta de dados. Depois da data-limite de preenchimento do questionário, transferiuse os dados ao Ms Excel de modo a gerir os resultados dos dados obtidos. Foram observadas questões relativas a frequência relativa e absoluta, aplicação de filtros e validou-se os dados.

\section{Caracterização dos participantes do estudo}

Deste estudo, participaram cento e dezassete (117) encarregados de educação, de uma base de cento e vinte (120) que responderam voluntariamente ao questionário disponibilizado online por meio das plataformas digitais (Facebook e WhatsApp). Portanto, trata-se de uma amostragem intencional, em que se buscou inquerir encarregados de educação usuários das redes sociais e que têm os filhos matriculados em escolas públicas e privadas de matriz nacional. Deste número, foram anulados três (3), pelo facto de seus filhos estarem matriculados em instituições de ensino que adoptam currículos de países estrangeiros, vulgo «colégios e escolas internacionais» autorizadas em Angola. Dos cento e dezassete (117) encarregados de educação participantes no estudo, $58,1 \%$ são do sexo feminino e $41,9 \%$ do masculino.

Importa referir que a distribuição de encarregados de educação em termos de sexo está alinhada com os dados da população angolana em que a maioria é feminina, 13.289.983, correspondente a $52 \%$ do total, enquanto a população masculina é de 12.499 .041 , representando $48 \%$ do total da população. Estes dados são do Censo populacional de 2014, que concluiu que a população em 
Angola, à data do momento censitário, 16 de Maio de 2014, era de vinte e cinco milhões, setecentos e oitenta e nove mil e vinte e quatro (25.789.024) pessoas (Instituto Nacional de Estatística, 2016). No ano de 2020, estimava-se que a população do país girasse em torno de (30.000.000) trinta milhões de habitantes, sendo a maioria feminina.

Dos encarregados de educação participantes neste estudo, 29,1\% tem as idades compreendidas entre os 36 a 40 anos, 21,4\% dos 41 a 45 anos, 20,5\% entre 31 a 35 anos. Depois, registam-se as percentagens de encarregados de educação com menores idades, nomeadamente, $12,8 \% \mathrm{com}$ as idades entre os 26 a 30 anos e $2,6 \%$ com as idades entre 21 a 25 anos. Entre as maiores idades, $2,6 \%$ com idades acima dos 55 anos, $4,3 \%$ dos 51 a 55 anos, e 6,8\% dos 46 a 50 anos de idade. É importante referenciar que 32,8\% da população angolana (numa ordem de 8.295.160), segundo dados do Censo populacional 2014, tem as idades compreendidas entre os 25 a 64 anos, que se encaixam dentro da amostra de encarregados de educação participantes no estudo. Ademais, em termos de idade, são mais ou menos correspondentes à idade dos encarregados de educação que têm filhos em idade escolar.

Quadro 2 - Caracterização dos encarregados de educação quanto à faixa etária.

\begin{tabular}{ccc}
\hline Faixa Etária & Fr. & Percentagem (\%) \\
\hline Dos 21 aos 25 anos & 3 & 2,6 \\
\hline Dos 26 aos 30 anos & 15 & 12,8 \\
\hline Dos 31 aos 35 anos & 24 & 20,5 \\
\hline Dos 36 aos 40 anos & 34 & 29,1 \\
\hline Dos 41 aos 45 anos & 25 & 21,4 \\
\hline Dos 46 aos 50 anos & 8 & 6,8 \\
\hline Dos 51 aos 55 anos & 5 & 4,3 \\
\hline Acima de 55 anos & 3 & 2,6 \\
\hline Total & $\mathbf{1 1 7}$ & $\mathbf{1 0 0}$
\end{tabular}

Fonte: Dados adquiridos do questionário aplicado aos encarregados de educação, 2020.

Um quarto dos encarregados de educação deste estudo tem três (3) filhos que frequentam uma escola, 24,8\% dos encarregados de educação, que corresponde a vinte e nove (29) dos cento e dezassete (117) participantes, $23,9 \%$ tem um filho e 23,1\% tem dois filhos. Já 21,4\%, ou seja, a soma dos encarregados de educação tem de quatro (4) até mais de cinco (5), conforme se pode verificar no quadro abaixo.

Quadro 3 - Número de filhos que frequenta a escola por encarregado de educação

\begin{tabular}{ccc}
\hline $\begin{array}{c}\text { Filhos por encarregado de } \\
\text { educação }\end{array}$ & $\mathbf{N}^{\mathbf{}}{ }^{\mathbf{o}}$ de inquiridos & Percentagem (\%) \\
\hline Nenhum & 8 & 6,8 \\
\hline Um & 28 & 23,9 \\
\hline Dois & 27 & 23,1 \\
\hline Três & 29 & 24,8 \\
\hline Quatro & 13 & 11,1 \\
\hline Cinco & 5 & 4,3 \\
\hline Mais de Cinco & 7 & 6 \\
\hline Total & $\mathbf{1 1 7}$ & $\mathbf{1 0 0}$
\end{tabular}

Fonte: Dados adquiridos do questionário aplicado aos encarregados de educação, 2020.

No que se refere às habilitações académicas dos 117 participantes, 54,7\% são licenciados, 24,8\% frequentam um curso de licenciatura, 9,4\% possuem o grau de mestre, 5,1\% são técnicos médios, 
2,6\% são doutores, $1,7 \%$ estavam a frequentar o ensino médio, $0,9 \%$ tem o ensino básico e igual número nunca estudou.

Relativamente às habilitações académicas, trata-se de uma amostra "superior" da população, extremamente selecionada. É de realçar que isto é habitual nos questionários online, na medida que além de ser alfabetizado funcional, é preciso ter computador, Internet e saber funcionar com ele. Regista-se que somente $7,7 \%$ da amostra não tem formação superior.

Os dados sobre a formação académica dos encarregados de educação neste estudo configuram de alguma importância, na medida em que no país este indicador vem sendo apontado como um dos factores condicionantes da representação social da escola juntos dos agregados familiares, bem como no acompanhamento da educação e instrução dos filhos e/ou educandos. Dados do Instituto Nacional de Estatística sugerem que 22\% das mulheres e 8\% dos homens, de 15 a 49 anos, nunca frequentaram a escola e aproximadamente um terço (33\%) das mulheres e $16 \%$ dos homens, de 15 a 24 anos, não sabem ler (Instituto Nacional de Estatística, 2016). Portanto, este aspecto tende a limitar a capacidade dos pais e encarregados de educação de participarem do processo de educação dos seus filhos, nomeadamente no que se refere ao auxílio na realização das tarefas orientadas pelos professores e outras actividades didáticas.

Quadro 4 - Distribuição dos encarregados de educação por habilitações académicas

\begin{tabular}{ccc} 
Habilitações académicas & $\begin{array}{c}\mathbf{N .}^{\mathbf{0}} \mathbf{d e} \\
\text { inquiridos }\end{array}$ & Percentagem $\mathbf{( \% )}$ \\
\hline Doutor & 3 & 2,6 \\
\hline Mestre & 11 & 9,4 \\
\hline Licenciado & $\mathbf{6 4}$ & $\mathbf{5 4 , 7}$ \\
\hline Licenciatura a frequentar & 29 & 24,8 \\
\hline Técnico Médio & 6 & 5,1 \\
\hline Ensino médio a Frequentar & 2 & 1,7 \\
\hline Técnico Básico & 1 & 0,9 \\
\hline Nunca estudei & 1 & 0,9 \\
\hline Total & $\mathbf{1 1 7}$ & $\mathbf{1 0 0}$
\end{tabular}

Fonte: Dados adquiridos do questionário aplicado aos encarregados de educação, 2020.

A distribuição geográfica dos encarregados de educação permite perceber que estão maioritariamente em Luanda, tendo em conta que das cento e dezassete (117) respostas obtidas, oitenta e quatro (84), que perfaz $71,8 \%$ de encarregados de educação, são residentes nesta província. Não obstante ao facto de o referido questionário ter sido destinado a todos os encarregados de educação do país, registaram-se respostas de um número reduzido de encarregados de educação de mais catorze (14) províncias. Portanto, essencialmente, são encarregados de educação de meio urbano.

Esta discrepância da participação dos encarregados de educação pode por um lado estar associada à dificuldade de acesso à Internet e de uso das plataformas digitais, considerando que a distribuição do questionário e a sua divulgação foi feita por via das redes sociais Facebook e Whats App. Por outro lado, podemos considerar o facto da maioria da população por razões socioeconómicas fundamentalmente, referir viver na província capital do país. Essa tendência se confirma nos dados do censo populacional de 2014, que aponta que um pouco mais de $27 \%$ da população do país vive em Luanda (Instituto Nacional de Estatística, 2016).

Quadro 5 - Distribuição geográfica dos encarregados de educação

\begin{tabular}{|c|c|c|}
\hline Zonas de residências & $\mathbf{N}^{\circ}$ de inquiridos & \\
\hline
\end{tabular}

\begin{tabular}{ccc}
\hline Bengo & 2 & 1,7 \\
\hline Benguela & 2 & 1,7 \\
\hline Bié & 1 & 0,9 \\
\hline
\end{tabular}




\begin{tabular}{ccc}
\hline Cabinda & 6 & 5,1 \\
\hline Cuanza Sul & 2 & 1,7 \\
\hline Huila & 8 & 6,8 \\
\hline Luanda & $\mathbf{8 4}$ & $\mathbf{7 1 , 8}$ \\
\hline Lunda Norte & 2 & 1,7 \\
\hline Lunda Sul & 1 & 0,9 \\
\hline Malanje & 1 & 0,9 \\
\hline Moxico & 3 & 2,6 \\
\hline Namibe & 3 & 2,6 \\
\hline Uige & 1 & 0,9 \\
\hline Zaire & 1 & 0,9 \\
\hline Total & $\mathbf{1 1 7}$ & $\mathbf{1 0 0}$
\end{tabular}

Fonte: Dados adquiridos do questionário aplicado aos encarregados de educação, 2020.

Quanto ao domínio de instituição de ensino, dos encarregados de educação participantes do estudo, $57,3 \%$ tem os filhos matriculados numa escola privada e 42,7\% em escola pública. É de referir que não foram colectados dados de encarregados de educação que tinham os filhos matriculados em escolas público-privadas, vulgo comparticipadas, onde o Estado assume, por exemplo, o pagamento de salários dos professores efectivos e comparticipa em principais despesas de bens e serviços, tal como estabelece o número 4 do artigo 98. ${ }^{\circ}$ da lei de Bases do Sistema de Educação e Ensino em Angola, ao prever que "considerando o interesse público, o Estado pode cofinanciar instituições de ensino de iniciativa privada em regime de parceira" (Assembleia Nacional, 2020b).

Quadro 6-Domínio da instituição de ensino que o filho frequenta

\begin{tabular}{c|c|c} 
Domínio de Instituição & $\begin{array}{c}\mathbf{N}^{\mathbf{o}} \text { de } \\
\text { inquiridos }\end{array}$ & $\begin{array}{c}\text { Percentagem } \\
\mathbf{( \% )}\end{array}$ \\
\hline Público & 50 & $42,7 \%$ \\
\hline Privado & 67 & $57,3 \%$ \\
\hline Total & 117 & $100 \%$
\end{tabular}

Fonte: Dados adquiridos do questionário aplicado aos encarregados de educação, 2020.

\section{Âmbito e Limitações do Estudo}

O presente estudo reflecte os resultados obtidos do inquérito realizado junto dos encarregados de educação da província de Luanda, tendo em conta que representam $71,8 \%$ dos participantes do estudo. Portanto, podem não representar a visão da totalidade da população em estudo pelo facto de o inquérito ter sido realizado numa altura em que as famílias estavam a cumprir o confinamento social, isto é, durante o Estado de Emergência. Todavia, em termos de representatividade pode servir de um bom indicador para avaliação do impacto das tele-aulas em Angola.

\section{Apresentação e análise dos resultados}

Os resultados do inquérito aplicado aos encarregados de educação revelaram que $68,4 \%$ dos seus filhos assistiu às tele-aulas, 7,7\% acompanhou tanto as tele-aulas quanto as rádio-aulas, enquanto 23,1\% não acompanhou nenhuma aula, ou seja, não assistiu as tele-aulas e nem ouviu as rádioaulas. Importa destacar que os alunos que não acompanharam nenhuma das aulas são filhos de encarregados de educação com formação superior, nomeadamente 10,2\% (12 encarregados de educação) licenciados e 6,8\% (8 encarregados de educação) a frequentar um curso de Licenciatura. Esses dados podem indicar alguma desatenção e/ou despreocupação da parte destes encarregados de educação, pois em função da sua habilitação literária seria expectável que tivessem uma melhor orientação sobre a importância do ensino a distância para o preenchimento das lacunas do ensino 
presencial que foi suspenso em razão da prevenção e combate da pandemia da COVID-19. Importa referir que entre as crianças que assistiram as tele-aulas, 47 são filhos de encarregados de educação licenciados, que corresponde a $40,1 \%$ da nossa amostra, por esta razão pode supor-se que aqueles que não acompanharam nenhuma das aulas sejam por distracção e/ou despreocupação dos encarregados de educação.

Quadro 7 - Encarregados de educação segundo as habilitações literárias e assistência dos filhos a tele-aulas

\begin{tabular}{cccccccc}
\hline $\begin{array}{c}\text { Habilitações } \\
\text { dos } \\
\text { encarregados } \\
\text { de educação }\end{array}$ & $\begin{array}{c}\text { Tipos de Aula } \\
\text { Rádio } \\
\text { aulas }\end{array}$ & $\begin{array}{c}\text { Tele- } \\
\text { aulas }\end{array}$ & $\begin{array}{c}\text { Rádio aulas } \\
\text { e Tele-aulas }\end{array}$ & $\begin{array}{c}\text { Nenhuma } \\
\text { aula }\end{array}$ & & \\
\hline Doutor & 1 & 1 & - & 1 & $\mathbf{3}$ & $\mathbf{2 , 6}$ \\
\hline Mestre & - & 11 & - & - & $\mathbf{1 1}$ & $\mathbf{9 , 4}$ \\
\hline Licenciado & - & 47 & 5 & 12 & $\mathbf{6 4}$ & $\mathbf{5 4 , 7}$ \\
\hline Lic. a frequentar & - & 17 & 4 & 8 & $\mathbf{2 9}$ & $\mathbf{2 4 , 8}$ \\
\hline Técnico Médio & - & 2 & - & 4 & $\mathbf{6}$ & $\mathbf{5 , 1}$ \\
\hline E.M. a frequentar & - & 1 & - & 1 & $\mathbf{2}$ & $\mathbf{1 , 7}$ \\
\hline Técnico Básico & - & 1 & - & - & $\mathbf{1}$ & $\mathbf{0 , 9}$ \\
\hline Nunca estudei & - & - & - & 1 & $\mathbf{1}$ & $\mathbf{0 , 9}$ \\
\hline Total & $\mathbf{1}$ & $\mathbf{8 0}$ & $\mathbf{9}$ & $\mathbf{2 7}$ & $\mathbf{1 1 7}$ & $\mathbf{1 0 0}$ \\
\hline $\mathbf{0}$ & $\mathbf{0 , 9}$ & $\mathbf{6 8 , 4}$ & $\mathbf{7 , 7}$ & $\mathbf{2 3 , 1}$ & $\mathbf{1 0 0}$ \\
\hline
\end{tabular}

Fonte: Dados adquiridos do questionário aplicado aos encarregados de educação, 2020.

Quanto à frequência do acompanhamento das tele-aulas, se pode perceber que a maioria dos filhos dos encarregados de educação participantes no estudo apresenta alguma regularidade no acompanhamento, sendo que $34,2 \%$ acompanha todas as aulas e $42,7 \%$ acompanha algumas vezes por semana, o que perfaz 76,9\% da amostra do estudo. Por outro lado, 23,1\% nunca acompanha as tele-aulas nem as rádio-aulas. Esta informação requer uma análise criteriosa no sentido de se apurarem as razões que condicionaram algumas crianças a não tirarem proveito das tele-aulas que tinha como propósito permitir a continuidade do processo de ensino-aprendizagem dos alunos durante o período de suspensão das aulas presenciais.

Quadro 8 - Encarregados de educação e acompanhamento dos filhos durante as Tela-aulas

\begin{tabular}{ccc}
\hline Frequência & $\mathbf{N}^{\mathbf{0}}$ de inquiridos & Percentagem (\%) \\
\hline Sim em todas as aulas & 40 & 34,2 \\
\hline Em Algumas aulas & 50 & 42,7 \\
\hline Não & 27 & 23,1 \\
\hline Total & $\mathbf{1 1 7}$ & $\mathbf{1 0 0}$
\end{tabular}

Fonte: Dados adquiridos do questionário aplicado aos encarregados de educação, 2020.

Tendo em conta que alguns encarregados de educação afirmaram que seus filhos não acompanham as tele-aulas, buscou-se saber que razões que impedem as crianças de as acompanhar e os resultados do inquérito levam a compreensão de que 47\% não teve uma razão que as devesse impossibilitar de acompanhar, ou seja, estas crianças não tinham nenhum impedimento. De outro lado, estão as $17,9 \%$ de crianças que não acompanhou as aulas por causa dos cortes constantes de energia, $12 \%$ por não conhecerem o horário das aulas, 9,4\% por falta de energia (supõe-se que seja, as crianças das zonas sem acesso à rede pública de energia eléctrica), 6,8\% por distração (estar desatento enquanto as aulas são transmitidas), 4,3\% por não ter sinal de televisão satélite e 2,6\% de crianças cujos encarregados de educação não têm o aparelho de televisão. 
Importa salientar que a amostra dos encarregados de educação que responderam ao questionário é essencialmente de áreas urbanas, residentes em Luanda e a maioria tem formação superior, o que em parte preocupa pelo facto de ainda assim seus filhos não terem acompanhado as aulas, mais do que isso apenas 2,6\% considerou não ter televisão (entre eles, um pai com a habilitação académica de Mestre e outro a frequentar a licenciatura) e 4,3\% alegou falta de sinal de televisão satélite (3 encarregados de educação Licenciados e 2 a frequentar a Licenciatura).

Estes dados são importantes, na medida em que impele que se busque compreender as possíveis razões que levam a que crianças de famílias com televisão não assistem às aulas. Por um lado, se pode deduzir que houve da parte de alguns encarregados de educação, uma desatenção e/ou incompreensão da importância que podem representar as tele-aulas para o desenvolvimento das crianças e a manutenção das suas rotinas de aprendizagem. Por outro lado, a questão do fornecimento da energia também pode ter conduzido a estes resultados, pois $27 \%$ das crianças não acompanharam por cortes constantes de energia $(17,9 \%)$ e outras por falta de energia $(9,4 \%)$.

Considerando que a amostra da avaliação das tele-aulas poder ser considerada da camada que correspondem aos níveis socioeconómico mais altos, pelas suas habilitações académicas (na ordem dos 66,7\% com Doutoramento, Mestrado e Licenciatura), ainda assim se ter registado dificuldades das crianças em acompanhar as aulas, se pode imaginar que nos meios em que a população é mais desfavorecida e menos instruída, que consequentemente não tiveram a oportunidade de responder ao inquérito, haveria mais problemas de acompanhamento das tele-aulas pelas crianças.

Quadro 9 - Tipos de obstáculos sentidas para os filhos não acompanharem as aulas

\begin{tabular}{|c|c|c|c|c|c|c|c|c|c|c|}
\hline \multirow[b]{2}{*}{ Obstáculo } & \multicolumn{8}{|c|}{ Habilitações Académicas dos encarregados de educação } & \multicolumn{2}{|c|}{ T. Geral } \\
\hline & DR. & M.Sc. & Lic. & $\begin{array}{l}\text { Lic. } \\
\text { Freq. }\end{array}$ & $\begin{array}{l}\text { Téc. } \\
\text { Médio }\end{array}$ & $\begin{array}{l}\text { E. M. } \\
\text { Freq. }\end{array}$ & $\begin{array}{l}\text { Téc. } \\
\text { Básico }\end{array}$ & $\begin{array}{l}\text { Nunca } \\
\text { estudei }\end{array}$ & N. ${ }^{\circ} \mathbf{I}$ & $\%$ \\
\hline $\begin{array}{c}\text { Ausência de } \\
\text { sinal de TV }\end{array}$ & - & - & 3 & 2 & - & - & - & - & 5 & 4,3 \\
\hline $\begin{array}{c}\text { Cortes } \\
\text { constantes de } \\
\text { energia } \\
\end{array}$ & - & - & 10 & 11 & - & - & - & - & 21 & 17,9 \\
\hline Distração & 1 & 1 & 6 & - & - & - & - & - & 8 & 6,8 \\
\hline $\begin{array}{c}\text { Falta de } \\
\text { energia }\end{array}$ & 1 & 1 & 4 & 3 & 1 & - & 1 & - & 11 & 9,4 \\
\hline $\begin{array}{l}\text { Não temos } \\
\text { TV }\end{array}$ & - & 1 & - & 1 & - & - & - & 1 & 3 & 2,6 \\
\hline $\begin{array}{c}\text { O não } \\
\text { conhecimento } \\
\text { do horário }\end{array}$ & - & 2 & 10 & - & 2 & - & - & - & 14 & 12 \\
\hline $\begin{array}{l}\text { Nenhuma } \\
\text { razão }\end{array}$ & 1 & 6 & 31 & 12 & 3 & 2 & - & - & 55 & 47 \\
\hline Subtotal & 3 & 11 & 64 & 29 & 6 & 2 & 1 & 1 & 117 & 100 \\
\hline$\%$ & 2,6 & 9,4 & 54,7 & 24,8 & 5,1 & 1,7 & 0,9 & 0,9 & 10 & 0 \\
\hline
\end{tabular}

Fonte: Dados adquiridos do questionário aplicado aos encarregados de educação, 2020.

Ainda em relação aos dados do quadro acima que identifica os tipos de obstáculos que as crianças tiveram para não acompanhar as tele-aulas, cuja base pode se fundamentar na questão da distribuição da energia eléctrica, impõe-se dizer que o acesso à energia, sinal de televisão e outros bens e serviços representam um problema real para a maioria dos agregados familiares em Angola. Segundo o Inquérito de Indicadores Múltiplos e de Saúde 2015-2016, realizado pelo Instituto Nacional de Estatística, 51\% dos aglomerados familiares em Angola tem acesso à televisão e à rádio. A posse de rádio é de $63 \%$ nas áreas urbanas, contra 32\% nas áreas rurais. A fruição de televisão é de $75 \%$ nas áreas urbanas, contra $14 \%$ nas áreas rurais. Já o acesso à energia eléctrica é 
limitado a apenas $42 \%$ dos agregados familiares, principalmente nas zonas rurais. Quanto ao uso do computador, apenas 13\% dos agregados familiares possuem computador em casa. Este quadro ainda se agrava quando associado ao insuficiente acesso à Internet de qualidade em diversas regiões do país e à baixa literacia digital das famílias, onde $40 \%$ dos homens e $20 \%$ das mulheres já usaram a Internet, pelo menos uma vez, sendo que $37 \%$ dos homens e $18 \%$ das mulheres utilizaram a Internet pelo menos 1 vez nos últimos 12 meses.

Estes indicadores, podem exigir que o olhar sobre as tele-aulas e o ensino a distância no que as medidas de política dizem respeito, deva ser mais abrangente de modo que, ao serem disponibilizadas possam alcançar a maioria da população estudantil angolana, sobretudo aquelas que até ao momento tem problemas de acesso à eletricidade, à rádio, à televisão e à Internet em suas residências.

No que se refere ao acompanhamento dos filhos durante as aulas, os resultados do estudo revelam que apesar de algumas dificuldades apresentadas no quadro anterior, no conjunto dos cerca de $77 \%$ das crianças que assistiram as aulas, os encarregados de educação acompanharam durante as tele-aulas, sendo que $42,7 \%$ em algumas as aulas e $34,2 \%$ em todas as aulas. Em posição contrária, encontram-se $23,1 \%$ que não acompanhou, sendo óbvio que se as crianças não assistem as aulas, os encarregados de educação não acompanham. Assim, é importante dizer que a participação dos encarregados de educação nas actividades de aprendizagem dos filhos acaba sempre por ter impacto positivo não só no rendimento escolar, como no desenvolvimento intelectual, emocional e social, e é um elemento motivacional para estes, tal como aponta Brás (2018), pelo que se aconselha que isso seja uma prática frequente.

Quadro 10 - Acompanhamento dos encarregados de educação aos filhos durante as aulas

\begin{tabular}{ccc} 
Frequência & N. $^{\mathbf{0}}$ de inquiridos & Percentagem (\%) \\
\hline Sim em todas as aulas & 40 & 34,2 \\
\hline Em Algumas aulas & 50 & 42,7 \\
\hline Não & 27 & 23,1 \\
\hline Total & $\mathbf{1 1 7}$ & $\mathbf{1 0 0}$
\end{tabular}

Fonte: Dados adquiridos do questionário aplicado aos encarregados de educação, 2020.

Ainda em relação ao acompanhamento dos encarregados de educação na formação escolar dos filhos, os dados do quadro que se seguem atestam que $41 \%$ dos encarregados de educação sempre auxiliava seu filho na realização das tarefas orientadas pelos professores nas tele-aulas, 16,2\% auxiliava frequentemente e $15,4 \%$ às vezes. Em contrapartida, 4,2\% auxiliava com raridade, enquanto $23,1 \%$, que correspondente às crianças que não acompanham as tele-aulas, naturalmente não auxiliava.

Neste sentido, importa reforçar que o auxílio dos encarregados de educação e encarregados de educação é importante igualmente pelas razões acima aludidas. Portanto, pode ser considerada como indispensável. Outrossim, trata-se de uma oportunidade para alguns encarregados de educação reviverem os seus tempos de escola, ao poderem auxiliar os filhos nas tarefas orientadas pelos professores.

Quadro 11 - Auxílio aos filhos na realização das tarefas orientadas nas tele-aulas

\begin{tabular}{ccc}
\hline Respostas & $\mathbf{N} .^{\mathbf{0}}$ de inquiridos & Percentagem (\%) \\
\hline Sempre & 48 & 41 \\
\hline Frequentemente & 19 & 16,2 \\
\hline Ass vezes & 18 & 15,4 \\
\hline Raramente & 5 & 4,2 \\
\hline Nunca & 27 & 23,1 \\
\hline Total & $\mathbf{1 1 7}$ & $\mathbf{1 0 0}$
\end{tabular}

Fonte: Dados adquiridos do questionário aplicado aos encarregados de educação, 2020. 
Os resultados do inquérito junto aos encarregados de educação permitem ainda compreender que a maioria dos alunos da iniciação a nona classe, a que se destinavam as tele-aulas, cerca de $71,8 \%$ gostava das aulas, distribuídos da seguinte maneira: $23,1 \%$ gostava de todas aulas, $24,8 \%$ gostava da maioria e $23,9 \%$ gostava de algumas aulas. De outro lado, $5,1 \%$ não gostava de nenhuma aula e $23,1 \%$ não soube caracterizar a reacção de seus filhos, pois eles não acompanharam as aulas.

Quadro 12 - Reacção dos filhos às tele-aulas

\begin{tabular}{ccc}
\hline Reacções & N. $^{\mathbf{0}}$ de inquiridos & Percentagem (\%) \\
\hline Gostam de todas & 27 & 23,1 \\
\hline Gostam da maioria & 29 & 24,8 \\
\hline Gostam de algumas & 28 & 23,9 \\
\hline Não gostam de nenhuma & 6 & 5,1 \\
\hline Não sei dizer & 27 & 23,1 \\
\hline Total & $\mathbf{1 1 7}$ & $\mathbf{1 0 0}$
\end{tabular}

Fonte: Dados adquiridos do questionário aplicado aos encarregados de educação, 2020.

As tele-aulas tiveram uma avaliação positiva da parte dos encarregados de educação, tendo $61,5 \%$ ter considero-as boas, 10,2\% muito boas e 5,9\% considerado excelente. Apreciação contrária tiveram $11,1 \%$ que as consideraram más e $4,2 \%$ péssimas, enquanto $6,8 \%$ não manifestou a sua opinião, sendo que seus filhos não as acompanharam. É de destacar aqui o facto de alguns encarregados de educação que não assistiram as tele-aulas terem achado que as aulas eram boas (15) que corresponde a $12,8 \%$ da amostra do estudo e 3,4\% que as acharam más.

Quadro 13 - Avaliação das aulas pelos encarregados de educação e encarregados de educação

\begin{tabular}{cccccc}
\hline \multirow{2}{*}{ Aulas à distância } & \multicolumn{2}{c}{ Situação } & \multirow{2}{*}{ Total Geral } & \multirow{2}{*}{$\%$} \\
\cline { 2 - 5 } & Assisitu & Não assistiu & & \\
\hline Excelente & 7 & - & $\mathbf{7}$ & $\mathbf{5 , 9}$ \\
\hline Muito Boas & 12 & - & $\mathbf{1 2}$ & $\mathbf{1 0 , 2}$ \\
\hline Boas & 57 & 4 & $\mathbf{7 2}$ & $\mathbf{6 1 , 5}$ \\
\hline Más & 9 & - & $\mathbf{5}$ & $\mathbf{4 1 , 2}$ \\
\hline Péssima & 5 & 8 & $\mathbf{8}$ & $\mathbf{6 , 8}$ \\
\hline Neutro & - & $\mathbf{2 7}$ & $\mathbf{1 1 7}$ & $\mathbf{1 0 0}$ \\
\hline Subtotal & $\mathbf{9 0}$ &
\end{tabular}

Fonte: Dados adquiridos do questionário aplicado aos encarregados de educação, 2020.

Os encarregados de educação fizeram uma avaliação positiva das tele-aulas. Todavia, apontaram que elas deviam ser melhoradas maioritariamente na sua duração $(23,1 \%), 20,5 \%$ na metodologia utilizada pelo professor, $11,1 \%$ na linguagem do professor, $10,3 \%$ nos meios de ensino e igual percentagem na carga de informação (conteúdo) por aula. Como é obvio, 23,1\% que corresponde aos encarregados de educação cujos filhos não acompanharam, o que inicialmente supõe que os mesmos também não terão acompanhado e, portanto, não souberam dizer em que aspectos as tele-aulas deviam ser melhoradas.

Quadro 14 - Aspectos que devem melhorar nas tele-aulas

\begin{tabular}{ccc}
\hline Aspectos por melhorar & N. $^{\mathbf{0}}$ de inquiridos & Percentagem (\%) \\
\hline Duração das aulas & 27 & 23,1 \\
\hline Na carga de informação & 12 & 10,3 \\
\hline Na linguagem do professor & 13 & 11,1 \\
\hline Metodologia do Professor & 24 & 20,5 \\
\hline
\end{tabular}




\begin{tabular}{ccc}
\hline Nas Tarefas orientadas & 2 & 1,7 \\
\hline Nos meios de ensino & 12 & 10,3 \\
\hline Não sei dizer & 27 & 23,1 \\
\hline Total & $\mathbf{1 1 7}$ & $\mathbf{1 0 0}$
\end{tabular}

Fonte: Dados adquiridos do questionário aplicado aos encarregados de educação, 2020.

A iniciativa de transmissão das tele-aulas foi avaliada como positiva por parte dos encarregados de educação, $44 \%$ considerou-a excelente, $34 \%$ boa e $21 \%$ muito boa, que perfaz $99 \%$ da amostra do estudo. Isso pode sinalizar que a medida de política terá sido acertada ter sido uma boa resposta do sector da educação à suspensão das aulas presencias provocadas pela pandemia da COVID-19. Importa salientar que mesmo aqueles encarregados de educação cujos filhos não acompanharam as aulas (numa ordem de 23,1\%) consideraram que a adopção do ensino a distância por meio das tele-aulas foi uma boa iniciativa do Ministério da Educação.

Quadro 15 - Avaliação da iniciativa do MED em produzir as tele-aulas

\begin{tabular}{ccc}
\hline Avaliação & N. $^{\mathbf{0}}$ de inquiridos & Percentagem (\%) \\
\hline Excelente & 51 & 43,6 \\
\hline Muito Boa & 25 & 21,4 \\
\hline Boa & 40 & 34,2 \\
\hline Má & 1 & 0,9 \\
\hline Total & $\mathbf{1 1 7}$ & $\mathbf{1 0 0}$ \\
\hline
\end{tabular}

Fonte: Dados adquiridos do questionário aplicado aos encarregados de educação, 2020.

\section{Síntese dos Resultados do Inquérito}

Os resultados apresentados e analisados apontam que $68,4 \%$ das crianças a que se destinavam as tele-aulas puderam acompanhá-las, porém $23,1 \%$ não acompanhou, em termos de frequência $34,2 \%$ acompanhou todas as aulas e 42,7 acompanha algumas vezes por semana, entre aquelas que não acompanharam, $47 \%$ não teve nenhum impedimento, enquanto $17,9 \%$ de crianças foi por causa dos cortes constantes de energia, $12 \%$ por não conhecerem o horário das aulas, $9,4 \%$ por falta de energia (supõe-se que sejam as crianças das zonas sem acesso à rede pública de energia), $6,8 \%$ por distração (estar desatento enquanto as aulas são transmitidas), 4,3\% por não ter sinal de televisão satélite e $2,6 \%$ de crianças cujos encarregados de educação não têm o aparelho de televisão.

Ainda assim, 42,7\% das crianças teve o acompanhamento dos encarregados de educação em algumas as aulas e $34,2 \%$ em todas as aulas e de igual modo $41 \%$ destas crianças tiveram os encarregados de educação a auxiliar na realização das tarefas orientadas pelos professores nas teleaulas, $16,2 \%$ auxilia frequentemente e $15,4 \%$ às vezes. Sobre a avaliação das tele-aulas, compreendeu-se que $71,8 \%$ das crianças gostavam das aulas e $61,5 \%$ dos seus encarregados de educação consideram-nas boas, devendo ser melhorada quanto às metodologias utilizadas pelos professores $(20,5 \%)$.

Estes resultados revelam a necessidade de se prestar mais atenção ao alcance das tele-aulas nas zonas urbanas e rurais, uma vez que se regista ainda um débil fornecimento de energia elétrica, ausência de sinal de televisão e famílias que não dispõem de aparelhos de televisão.

Os resultados que chegamos neste estudo, foram também referenciados em outros estudos, nomeadamente no relatório da MOSAIKO que faz referência que apenas $22 \%$ das crianças (das 70 escolas inquiridas) assistiram as tele-aulas e rádio-aulas; $26 \%$ não as assistem por falta de energia eléctrica (Mosaiko \& Rede Etp-Angola, 2020, p.19).

O estudo desenvolvido pela Ovilongwa objectivava analisar o alcance, a satisfação e o impacto nas aprendizagens das tele e rádio aulas. Os investigadores concluíram que as tele-aulas e rádio-aulas foram seguidas por cerca de metade das famílias. Sendo que as tele-aulas foram mais seguidas do 
que as rádio-aulas. 69\% de pais e encarregados de educação dos alunos da educação pré-escolar e ensino primário, numa ordem de 5.221 inquiridos, afirmaram que acompanharam as aulas da televisão, 18\% acompanharam as aulas da televisão e rádio e $10 \%$ pela rádio. Em relação aos alunos, $78 \%$ dos inquiridos acompanharam as aulas pela televisão, 10\% acompanharam as aulas da televisão e rádio e apenas 3\% usaram unicamente a rádio (OVILONGWA, 2021).

Julião (2020, p.22) num estudo que teve como propósito averiguar o nível de socialização dos professores com as tecnologias educativas para apoiar o processo de ensino e aprendizagem num contexto de isolamento físico imposto pela COVID-19, aponta alguns professores inqueridos (numa ordem de 31 dos 69 inquiridos) possuem um conhecimento médio e basicamente teórico sobre as tecnologias educativas (44,9\% dos inquiridos), e o acesso as Tecnologias de Informação e Comunicação é baixo, por outro lado, muitos têm dificuldades de conectaram-se pela internet. De acordo o estudo, estas dificuldades são sentidas principalmente pelos alunos de famílias desfavorecidas.

Queria (2020) buscando compreender o alcance do desenvolvimento das capacidades de observar, anotar e analisar criticamente uma aula de Matemática a partir das aulas emitidas pela Televisão Pública de Angola durante o período de Estado de emergência, concluiu que o projecto de teleaulas foi uma oportunidade para os 51 estudantes que frequentavam a cadeira de Prática Pedagógica I do $3^{\circ}$ Ano do curso de Licenciatura em Ensino da Matemática no ISCED-Luanda de experimentarem uma alternativa à forma habitual de práticas.

Em termos de desenvolvimento de competências, o estudo de Bengo (2021) refere que o projecto das "tele-aulas" dado ao seu caráter prático contribuíram para a melhoria da atuação dos professores do ensino primário, ou seja, o professor do Ensino Primário passou a recorrer regularmente ao apoio tutorial de outros profissionais de educação e a atividade reflexiva, de modos aperfeiçoar as competências didático-pedagógicas, tais como a organização e contextualização dos conteúdos de ensino à realidade do aluno e maior conhecimento das orientações metodológicas das disciplinas do ensino básico.

O estado de implementação das tele-aulas e radio-aulas é desigual em estados africanos e outros estados do mundo, tanto no que se refere aos países industrializados como em países em via de desenvolvimento. O relatório de um estudo realizado em 52 países de África pelos especialistas em EdTech (educação e tecnologia) e pela rede eLearning Africa, sobre o impacto da pandemia COVID-19 na educação em África, reforça a pertinência de inclusão da TV e rádio nos processos de ensino-aprendizagem. Os resultados apontam que 55\% dos inquiridos consideram que a televisão e a rádio são as tecnologias mais importantes e relevantes para o ensino à distância orientado para os alunos do ensino primário. Portanto, a televisão e a rádio podem servir como recursos didáctico-pedagógico e método de comunicação mais útil para o ensino à distância ao nível do ensino primário" (EDTECHHUB \& ELEARNING AFRICA, 2020, p.18).

Edtechhub \& Elearning Africa (2020, pp.23-24) concluíram que entre os principais obstáculos enfrentados pelos países africano numa resposta efectiva à pandemia constam: "(i) a ausência de acesso a tecnologia e infra-estruturas eficazes (44\%) e a ausência de electricidade e ligação à internet com facilidade de acesso e a um preço acessível (49\%)".

É importante destacar que muitos países, como a Costa de Marfim, Quénia, Etiópia, Gana, Moçambique, Senegal, Etiópia avançaram com as aulas através da rádio e da televisão para manter o sistema de educação funcional. Em Moçambique, a estação de televisão pública nacional criou um canal "telescola", onde são lecionadas diariamente as aulas em directo (Save the Children International, 2020, pp.11-12)

De um modo geral, os países que assinaram ou que têm acordos com as empresas de telecomunicações, tiveram acesso e utilizaram dos serviços da estação televisiva e radiofónica de forma eficiente e eficaz desde a preparação e organização dos processos de transmissão, podendo assegurar a continuidade do ensino. A título de exemplo, a Argélia tem 12 canais de televisão para crianças, da $1^{\mathrm{a}}$ a $12^{\mathrm{a}}$ Classes para todas as disciplinas. No Botsuana, a televisão nacional transmitiu programas escolares e as empresas de telecomunicações distribuíram conteúdos. Estas medidas 
revelam a importância das parcerias para a garantia do direito à educação (EDTECHHUB \& ELEARNING AFRICA, 2020).

No Gana as aulas eram transmitidas pela TV de Aprendizagem, um canal de televisão que permite aos cerca de 900 mil alunos do ensino secundário continuar a sua formação. Na TV de Aprendizagem do Gana, as aulas começam às 8 h30 da manhã, como num dia normal de escola, com quarenta e cinco minutos de matemática para alunos do ensino secundário. Mas, o problema do Gana é igualmente parecido aos demais países africanos, pois de acordo com dados do Banco Mundial, $21 \%$ da população ganesa não tem acesso à energia. Razão pela qual, terão optado pela difusão das aulas na rádio, de modos que o maior número de crianças pudesse ter acesso aos mesmos (Save the Children International, 2020, p.11).

Estudando a realidade brasileira se pode verificar que a opção pela televisão e rádio como meios de mediação da aprendizagem em tempo de pandemia foram consideradas como os instrumentos mais adequados, tal como aponta Todos pela Educação, que considera que, em âmbito nacional e/ou regional, dois importantes veículos que devem ser considerados para assegurar amplo alcance são o rádio e a televisão (Todos Pela Educação, 2020). Esta organização apresenta números sobre o acesso à televisão no Brasil que favorecem a opção por tele-aulas:

A televisão já começa a figurar como parte importante da estratégia de alguns Estados, pesquisas mais recentes indicam que, nos mais de 70 milhões de domicílios no Brasil, sua penetração é de, aproximadamente, 96\%. Com efeito, tais estratégias têm capacidade restrita de customização do conteúdo, mas seu alcance quase universal não pode ser menosprezado pelas autoridades que podem aportar soluções em nível nacional ou em escala estadual (Todos Pela Educação, 2020, p.10).

Souza \& Aguiar (2020) apoiando-se em dados da Pesquisa Nacional de Amostra de Domicílios, realizada pelo Instituto Brasileiro de Geografia e Estatística, em 2018, apontam que 96,4\% dos domicílios tinham televisão. Quanto a adopção do ensino a distância por intermédio da televisão, estes autores apontam que o estado do Amazonas foi o primeiro a adoptar o ensino a distância na rede pública logo após a suspensão das aulas, no início da pandemia.

No estado do Amazonas, aos 23 de março teve início o programa Aula em Casa, em que as aulas anteriormente transmitidas para as salas de aula conectadas, passaram a ser veiculadas em multicanais digitais da TV Encontro das Águas, emissora pertencente ao governo do estado e afiliada da TV Brasil. Neste estado, as tele-aulas atingiram 450 mil estudantes vinculados à rede estadual e às redes municipais de ensino. Já no Estado da Bahia, as aulas remotas tiveram início em 30 de junho sendo exibidas em dois multicanais digitais, contando com a transmissão de aulas pela TV aberta, atingindo 500 mil alunos (Souza \& Aguiar, 2020, p.242).

Souza \& Aguiar (2020, p.242) apontam que no contexto brasileiro para os estudantes que não têm acesso à plataforma digital das instituições de ensino, as tele-aulas tiveram início em 6 de abril, transmitidas pela TV Justiça, emissora pública, e pela TV União e TV Gênesis, emissoras privadas locais que exibem os conteúdos em horários alternativos. Para efeitos da avaliação, as aulas exibidas pela televisão serão consideradas em seu valor pedagógico como meio de acesso dos estudantes ao conteúdo, porem, as atribuições de frequência, isto é, de avaliação contínua, serão realizadas mediante a entrega das atividades solicitadas pelos professores.

Porém, Bahia (2020) estudando a situação do Estado de São Paulo, adverte que nem todos os alunos da rede pública de ensino do Estado de São Paulo tinham acesso às plataformas e/ou ferramentas criadas pela Secretaria da Educação do Estado de São Paulo, pelas escolas ou pelos professores, como é o caso das aulas transmitidas pela TV Cultura. A autora considera que, não obstante não haver até à altura do seu estudo, dados oficiais e precisos sobre quantos alunos não dispunham desse acesso, "de 3,7 milhões de alunos, somente 1,5 milhão consegue aceder as aulas. Isso cria desigualdade para quem já é desigual socialmente, ainda mais em meio a uma pandemia (Bahia, 2020, p.120). Autora apresenta as diferenças situações que interferiram para que nem todos os alunos tivessem acesso às plataformas e/ou ferramentas criadas: 
"alunos que trabalham o dia todo e só conseguem acesso aos aplicativos à noite, alunos que dependem do uso do celular do pai, da mãe ou do responsável quando estes chegam do trabalho, famílias que possuem somente um celular e que têm dois ou três filhos que precisam do mesmo para participarem das aulas não presenciais, alunos que possuem computador, mas sem acesso à internet, pais/responsáveis que não possuem a menor condição de acompanhar/ajudar os filhos caso encontrem alguma dúvida/dificuldade para a realização de um trabalho e/ou exercício, alunos que não contam com um ambiente com condições mínimas para realizar seus estudos e a concentração que isso requer (porque moram em um cômodo com mais cinco ou seis pessoas), alunos que não possuem nenhum equipamento que lhes permita participar das aulas não presenciais (Bahia, 2020, p.123).

Todavia, as tele-aulas, ainda assim, constituíram uma boa alternativa a suspensão do ensino presencial neste país. Tal como sugere o estudo de Junior e Monteiro (2020), as aulas transmitidas pelo rádio e TV favorecem o processo de aprendizagem em tempo de distanciamento social e se apresentam como uma prática inclusiva, considerando que muitos alunos não têm acesso a outras tecnologias para acompanhar o conteúdo escolar.

Neste sentido, analisando estudos de autores e instituições sobre a realidade angolana, sobre a realidade em outros países africanos, bem como da realidade brasileira, podemos compreender que há uma aproximação e registos sobre a importância das tele-aulas, como metodologia alternativa no contexto da suspensão das aulas presenciais, motivadas pela pandemia. Há evidencias de dificuldades relacionadas ao acesso à emissão televisiva e na distribuição da corrente eléctrica, esta realidade angolana e africana pode implicar um handicap, ao contrário do Brasil, onde o acesso cobre mais de $90 \%$ dos agregados familiares.

\section{Considerações finais}

Este artigo reflectiu sobre os resultados da avaliação que os encarregados de educação de Luanda fizeram da implementação das tele-aulas como uma das respostas das autoridades do sector da educação ao impacto da suspensão das aulas presenciais no período de Estado de Emergência em Angola. Ele surgiu da necessidade de se compreender o grau de alcance das tele-aulas considerando a condição socioeconómica dos agregados familiares em Angola, marcada por dificuldades múltiplas, o que de certa forma acaba impactando na criação de condições para a formação dos filhos.

Os resultados do estudo sinalizam que a produção das tele-aulas foi uma boa alternativa à suspensão das aulas presenciais, apesar de $23,1 \%$ das crianças não as ter acompanhado por desatenção e falta de acompanhamento dos encarregados de educação, constantes de cortes de energia eléctrica e de sua falta em algumas zonas, associado à falta de sinal de televisão, bem como a não posse de aparelho de televisão da parte de alguns agregados familiares pela débil situação socioeconómica que os caracterizam.

Por outro lado, estes resultados podem dar algum fundamento a alguns cidadãos que as consideram como uma forma de "elitização" da educação, de discriminação e incremento das desigualdades sociais, alicerçados no argumento segundo qual as tele-aulas alcançariam mais os alunos das zonas urbanas e periurbanas, prejudicando os das zonas rurais.

Em síntese, pode-se constatar que existiram contrariedades em relação ao mecanismo alternativo adotado pelas autoridades do sector da educação para garantir a continuidade da aprendizagem das crianças. Ou seja, o ensino a distância por meio das tele-aulas não tiveram o alcance desejado pela débil situação socioeconómica das famílias, do fornecimento deficitário de electricidade no país e da desatenção de alguns encarregados de educação.

Estes resultados sinalizam que o contexto da pandemia desempenhou o papel de avaliador das lógicas de governo destinadas a efetivar a educação como direito dos cidadãos, sobretudo das crianças e jovens. Constatou-se, ainda, que existe um hiato entre o enunciado formal das políticas e efetivação destes, particularmente no quesito da mobilização de inputs para a realização da 
educação escolar formal. Esta deficiente mobilização de recursos tornou o sistema de educação inapto, salvaguardas às exceções, em ajustar-se aos desafios de apurar as técnicas e tecnologias disponíveis e mobilizá-las ao serviço da educação. Os problemas identificados não podem ser resumidos ao contexto da pandemia, pois é uma realidade permanente que precisa ser superada com políticas sustentáveis e eficazes.

\section{Referências bibliográficas}

Assembleia do Povo. (1991). Lei sobre o estado de sítio e estado de emergência. Lei n. ${ }^{\circ}$ 17/91, de 11 de Maio. Angola.

Assembleia Nacional. (2001). Lei de Bases do Sistema Educativo Angolano. Lei n. ${ }^{\circ}$ 13/01, de 31 de Dezembro. Angola.

Assembleia Nacional. (2016). Lei de Bases do Sistema de Educação e Ensino. Lei n. ${ }^{\circ}$ 17/16, de 7 de Outubro. Angola.

Assembleia Nacional. (2020a). Declaração do Estado de Emergência. Decreto Presidencial n. ${ }^{\circ}$ $81 / 20$, de 25 de Março. Angola.

Assembleia Nacional. (2020b). Lei que altera a lei n. ${ }^{\circ}$ 17/16, de 7 de outubro - Lei de Bases do Sistema de Educação e Ensino. Lei n. ${ }^{\circ}$ 32/20, de 12 de agosto. Angola.

Bahia, Norinês P. (2020). Pandemia!!! E Agora? Reflexões Sobre O Cotidiano Escolar A Distância. Cadernos CERU. Volume 31. No. 1. Brasil (pp.116-125). Disponível em: https://www.revistas.usp.br/ceru/article/view/174489.

Bengo, Nádia. (2021). Tele e Rádio Aulas: Aperfeiçoamento Profissional do Professor do Ensino Básico. SISYPHUS Journal of Education. Volume 9, Issue 01, Portugal (pp.61-83). https://doi.org/10.25749/sis.23404.

Brás, Chocolate. (2018). Educação e Valores em Angola: Compreender o papel da escola. Novas Edições Académicas. Alemanha.

Comissão Interministerial para as Emergências (2020). Plano Nacional de Contingência Para o Controlo da Epidemia de Doença por Coronavírus 2019 (COVID-19). Documento não editado. Angola.

Edtechhub \& Elearning Africa (2020). O Efeito da COVID-19 na Educação em África e Suas Implicações para a Utilização da Tecnologia. Um Inquérito sobre a Experiência e as Opiniões de Educadores e Especialistas em Tecnologia. September 2020. DOI 10.5281/zenodo.4018774. Disponível em: https://www.elearningafrica.com/conference/ressources/pdfs/surveys/The effect of Covid-

19 on Education in Africa pt.pdf.

Gil, António Carlos. (1999). Métodos e técnicas de pesquisa social. Atlas. Brasil.

Google. (2017). Google Apps Script. Overview of Google Apps Script. Disponível em: $<$ https://developers.google.com/apps-script/overview>. Consulta: 17/05/ 2020.

Instituto Nacional de Estatística. (2016). Resultados definitivos do Recenseamento Geral da População e da Habitação de Angola 2014. INE. Angola.

Instituto Nacional de Estatística. (2017). Inquérito de Indicadores Múltiplos e de Saúde. Documento não editado. Angola.

Instituto Nacional de Formação de Quadros da Educação. (2020). Relatório do II Trimestre das Tele-aulas e Rádio-aulas. Documento não editado. Angola.

Julião, António Luís. (2020). Professores, tecnologias educativas e COVID-19: realidades e desafios em Angola. Revista Angolana De Ciências. Volume 2, No. 2. Angola, (pp.125).

Disponível

em:

http://publicacoes.scientia.co.ao/ojs2/index.php/rac/article/view/105.

Junior, Verissimo Barros dos Santos \& Monteiro, Jean Carlos Silva. (2020). Covid-19 e escolas no ar: transmissão de aulas por rádio e tv aberta em período de distanciamento social. Boletim de Conjuntura. Volume 3, No. 8. Brasil (pp.6-16). http://doi.org/10.5281/zenodo.3930103. 
Mathias, Sergio Larruscaim \& Sakai, Celio. (2013). Utilização da Ferramenta Google Forms no Processo de Avaliação Institucional: Estudo de Caso nas Faculdades Magsul. Disponível em: http://download.inep.gov.br/educacao superior/avaliacao institucional/seminarios reg ionais/trabalhos regiao/2013/centro oeste/eixo 1/google forms processo avaliacao i nstit estudo caso faculdades mag.pdf.

Ministério da Educação. (2019). Relatório do Seminário Internacional sobre a Educação a Distância e Itinerante. Documento não editado. Angola.

Ministério da Educação. (2020a). Suspensão de Actividades Lectivas da Educação PréEscolar ao II Ciclo do Ensino Secundário. Decreto Executivo n. ${ }^{\circ}$ 01/20, de 19 de Março. Angola.

Ministério da Educação. (2020b). Apelo aos encarregados de educação sobre o acompanhamento dos filhos durante as teleaulas. Circular do Gabinete da Ministra da Educação, de 1 de Abril. Angola.

Ministério da Educação. (2020c). Recomendações para o funcionamento das escolas no período de suspensão das aulas. Decreto Executivo n. ${ }^{\circ}$ 02/20, de 20 de Março. Angola.

Ministério da Educação. (2020d). Plano de Emergência do sector da educação para resposta à Covid-19. Documentado não editado. Angola

Mosaiko \& Rede Etp-Angola. (2020). Diagnóstico às Escolas do Ensino Primário e I Ciclo sobre as condições de regresso às aulas, em tempos de COVID-19. Disponível em: https://mosaiko.op.org/wp-content/uploads/2019/05/Diagn \%C3\%B3stico-dascondi $\% \mathrm{C} 3 \% \mathrm{~A} 7 \% \mathrm{C} 3 \% \mathrm{~B} 5$ es-das-escolas-para-regresso- $\% \mathrm{C} 3 \% \mathrm{~A} 0$ saulas Angola 2020.pdf

OCDE. (2020). Um roteiro para guiar a resposta educacional à Pandemia da COVID-19 de 2020. Disponivel em: https://www.oecd-ilibrary.org/education/um-roteiro-para-guiar-a-respostaeducacional-a-pandemia-da-covid-19-de-2020 da7015da-pt. Consulta: 17/05/2020.

Organização Mundial da Saúde. (2020a). Conferência de imprensa de 1 de Janeiro). OMS.

Organização Mundial da Saúde. (2020b). Conferência de imprensa de 30 de Janeiro de 2020. OMS.

OVILONGWA. (2020). Relatório de Estudo sobre as Tele e Rádio Aulas: O Alcance, a Satisfação e o Impacto na Aprendizagem. Documento não editado. Angola.

Queria, Mbiyavanga. (2020). As tele aulas de Matemática durante o Estado de Emergência: Experiências e Lições. Revista Angolana de Extensão Universitária. Volume 2, No. 3. Angola (pp.89-105) Disponível em: https://www.portalpensador.com/index.php/RAEU-BENGO/article/view/196/148.

Save the Children International (2020). Impactos da Covid-19 nas crianças africanas. Como proteger uma geração em risco. Disponível em: https://resourcecentre.savethechildren.net/node/17694/pdf/pan african policy paper - portugese version.pdf.

Souza, Fernando Moreira. (2020). O papel da TV digital no ensino remoto em tempos de pandemia. Comunicação \& Inovação. Volume 21, No. 47. Brasil (pp.232-249). Disponível em: https://seer.uscs.edu.br/index.php/revista comunicacao inovacao/article/download/7 220/3191/23216.

Televisão Pública de Angola. (2020). Telejornal do dia 1 de Abril de 2020. Angola.

Todos Pela Educação. (2020). Ensino a distância na educação básica frente à pandemia da COVID-19. em: https://www.todospelaeducacao.org.br/ uploads/ posts/425.pdf. 
UNESCO (2020a). COVID-19 deixa mais de 776 milhões de alunos fora da escola. Disponível em: https://pt.unesco.org/news/covid-19-como-coalizao-global-educacao-da-unescoesta-lidando-com-maior-interrupcao-da.

UNESCO. (2020b). 10 Recomendações sobre ensino a distância devido ao novo coronavírus. Disponível em: https://pt.unesco.org/news/covid-19-10-recomendacoesplanejar-solucoes-aprendizagem-distancia. 